\title{
DECLÍNIO DA PRODUÇÃO DE MANDIOCA: OS IMPACTOS ECONÔMICOS NO MUNICÍPIO DE SANTA IZABEL, ESTADO DO PARÁ
}

\author{
Francisco de Assis Pinto Bezerra'. \\ ${ }^{1}$ Mestre em Planejamento do Desenvolvimento pelo Núcleo de Altos Estudos Amazônicos, Universidade \\ Federal do Pará. Belém, Pará, Brasil. pinto.bezerra@hotmail.com.
}

RESUMO: O artigo objetivou avaliar os impactos socioeconômicos do declínio da produção da mandioca no município de Santa Isabel do Pará e, para tanto, aplicou-se questionário à população de produtores de farinha de tapioca do Distrito de Americano, cujos dados resultaram na descrição das estatísticas econômicas desta atividade. A pesquisa revelou que vários elementos contribuíram para desequilibrar e encerrar o padrão de produção da mandioca, que por mais de um século foi à base da economia local. Para se manter no campo, os ex-produtores se deslocaram para o ramo da farinha de tapioca, cujo insumo básico - a fécula é importada do Paraná. O esgotamento do ciclo da produção de mandioca causou pouco impacto na economia local, pois a receita gerada na tapioca foi superior aos resultados econômicos dos anos de 1970, ocasião do ápice da mandioca, embora se questione a internalização da renda gerada na tapioca, em função do envio de parte significativa da sua receita para fora do estado. Constatou-se ainda alterações na estrutura do emprego, trabalho e na composição da mão de obra familiar, com profundos desequilíbrios nas atividades agrícolas, reflexo do acentuado processo de urbanização no meio rural, que desloca a populacional para as cidades.

PALAVRAS-CHAVE: Economia. Farinha de tapioca. Produtores. Urbanização.

\section{DECLINE IN CASSAVA PRODUCTION: THE ECONOMIC IMPACTS IN THE MUNICIPALITY OF SANTA ISABEL, STATE OF PARA}

\begin{abstract}
The article aimed to assess the socioeconomic impacts of the decline in cassava production in the municipality of Santa Isabel do Pará and, therefore, the questionnaire was applied to the population of producers of tapioca flour American District, whose data have resulted in the description of economic statistics this activity. The survey revealed that several factors contributed to disrupt and end the pattern of production of cassava, which for over a century was the mainstay of the local economy. To remain in the field, former producers moved to the branch of tapioca flour, whose basic input - the starch is imported from Paraná. The depletion of cassava production cycle has had little impact on the local economy because the revenue generated in the tapioca was higher than the economic results of 1970, during the apex of cassava, although questioning the internalization of the income generated in tapioca, depending sending a significant portion of its revenue out of the state. Still found changes in the structure of employment, work and composition of family labor, with deep imbalances in agricultural activities, reflecting the severe process of urbanization in rural areas, which shifts the population to the cities.
\end{abstract}

KEYWORDS: Economy. Producers. Tapioca flour. Urbanization. 


\section{DISMINUCIÓN DE LA PRODUCCIÓN DE YUCA: LOS IMPACTOS ECONÓMICOS EN LA CIUDAD DE SANTA IZABEL, ESTADO DE PARÁ}

RESUMEN: Este artículo tiene como objetivo evaluar los impactos socioeconómicos de la disminución de la producción de yuca en el municipio de Santa Isabel do Pará y por lo tanto, el cuestionario se aplicó a la población de productores de tapioca harina Distrito Americano, cuyos datos se han traducido en la descripción de estadísticas económicas de esta actividad. La encuesta reveló que varios elementos contribuyeron a desestabilizar y acabar con el patrón de la producción de yuca, que durante más de un siglo fue el pilar de la economía local. Para permanecer en el campo, los antiguos productores se trasladaron a la rama de la harina de tapioca, cuyo insumo básico - el almidón ha sido importada desde Paraná . El agotamiento del ciclo de producción de yuca ha tenido poco impacto en la economía local debido a los ingresos generados en la tapioca fue superior a los resultados económicos de 1970, durante la cúspide de la yuca, aunque cuestionando la internalización de las rentas generadas en tapioca, dependiendo el envío de una parte significativa de sus ingresos fuera del estado. Fue también encontró cambios en la estructura del empleo, el trabajo y la composición de la mano de obra familiar, con profundos desequilibrios en las actividades agrícolas, lo que refleja la fuerte proceso de urbanización en las zonas rurales, que desplaza a la población a las ciudades.

PALABRAS-CLAVE: Economía. Harina de tapioca. Productores. Urbanización.

\section{INTRODUÇÃO}

Autores, como Albuquerque (1970), Lozano et al. (1976) e Cardoso (1993), consideram a mandioca (Manihot esculenta Crantz) como uma cultura milenar e base da alimentação das populações primitivas e rurais nas regiões intertropicais do planeta, visto que a cultura exige sol e chuva para se reproduzir.

Dados estatísticos do Fundo das Nações Unidas para a Agricultura e Alimentação (FAO) informam que do total da mandioca produzida nas regiões africanas e latinas, $58 \%$ é destinada para o consumo humano, $22 \%$ para o consumo animal e $20 \%$ para o uso industrial (FAO, 2006), indicando a extrema dependência das populações de menor poder aquisitivo a mandioca.

Nessas regiões menos desenvolvidas, como na África e na Amazônia, a mandioca é orientada, predominantemente, para a produção de farinha, cujo consumo se realiza como complemento alimentar nas principais refeições diárias, sendo mais 
representativa dentre as camadas sociais de baixo poder econômico (ALBUQUERQUE, 1996; HOMMA, 2000; FIGUEIREDO, 2001). Na África, notadamente na região do Congo, o consumo per capita de farinha de mandioca representa $330 \mathrm{~kg} / \mathrm{ano}$ (FAO, 2006). No Brasil, segundo levantamentos da Secretária de Planejamento e Orçamento das Finanças Públicas (SEPOF), o maior demandante per capita da farinha de mandioca é o Estado do Pará (43 Kg), seguido pelo Estado de Fortaleza, que apresenta um consumo de $15 \mathrm{Kg}$ (PARÁ, 2004), embora a mandioca venha sendo explorada para outros fins ${ }^{1}$.

Corrobora também a importância da mandioca como alimento humano a Empresa Brasileira Agropecuária (EMBRAPA), ao afirmar que esta cultura é responsável pela alimentação de mais de um bilhão de pessoas no mundo (EMBRAPA, 2005). Além de ser fonte de alimento para milhares de pessoas no mundo, a mandioca ocupa e

1 Estudos da Associação dos Produtores de Amido de Mandioca (ABAM) mostram que vem se intensificando a exploração da fécula de mandioca (goma), principalmente no Brasil e Ásia, um subproduto que vem sendo experimentado em diversas linhas do ramo industrial, como no setor de papel, alimento, tecido, entre outros, reflexo da aplicação de elevado nível tecnológico que transforma a raiz, abrindo possibilidades de uso para essa tradicional cultura. fixa o homem no campo, ao gerar trabalho e renda, dada a sua natureza de envolver a mão de obra familiar. Por esta importância, Albuquerque (1969) considerou a mandioca como uma das culturas sociais que predomina no Brasil.

Portanto, a representativa da mandioca como alimento e ocupação no campo é uma forte justificativa para desenvolver este artigo, além de contribuir com a ciência para explicar a presença e o comportamento dessa tradicional cultura no atual momento contemporâneo e global.

Muito embora da forte dependência socioeconômica das famílias rurais e de menor poder aquisitivo à mandioca, em algumas regiões tradicionais na produção, a exemplo do Município de Santa Izabel, esta cultura vem perdendo a referência, colocando em risco a permanência do homem no campo e/ou deslocando produtores para outras atividades, seja dentro ou fora da agricultura, implicando nas variáveis de emprego, renda e do Produto Interno Bruto (PIB) rural ${ }^{2}$.

\footnotetext{
${ }^{2}$ Até o final da década de 1970, este município, a partir do Distrito de Americano, representava fonte de abastecimento de farinha de mandioca e derivados básicos para as feiras livres da metrópole paraense e adjacências, além de
} 
Esta dificuldade de reprodução e de permanência da unidade familiar no espaço rural, inclusive, fora objeto de discussão entre autores internacionais no século XIX, com destaque a Goodman et al. (1989), Chayanov (1981) e Kautsky (1987). No Brasil, o debate na academia sobre a trajetória dos produtores rurais se acirrou a partir dos anos de 1980, com maior visibilidade nas obras de Szmrecsányi (1998), Silva (2002) e Abramovay (1992).

No caso do ramo da mandioca, o elemento camponês é mais sensível à mobilidade, pois as famílias rurais são extremamente dependentes desta atividade, seja por ser intensa na ocupação de mão de obra, seja por ocupar um espaço tão crucial na vida familiar camponesa, como fonte de alimento. Esta intima relação entre a mandioca e a população camponesa tem escopo nos estudos de Abramovay (1992, p. 116), ao afirmar que "a mandioca, como produto alimentar, amplia a margem de opções do camponês, embora demande intenso esforço físico". Este problema de risco de permanência dos produtores de mandioca no espaço rural, bem como às

exportar para Macapá e alguns Estados nordestinos. atividades ligadas a esta matéria prima, gerou o grande interesse e motivação para se tomar a mandioca como objeto de estudo neste artigo

O mais grave, é que o risco de reprodução das famílias rurais não é algo exclusivo dos campos do nordeste paraense ou da Amazônia, pois este fenômeno se reproduz também no resto do país, como no estado de São Paulo, uma vez que as atividades agropecuárias tradicionais, sozinhas, não deram conta de explicar a dinâmica de emprego, renda e população nesta região, efeito do processo de urbanização rural (SILVA, apud COUTO, 1998, p. 913). Essa questão se reproduz também em nível mundial, pois na França dos $27 \%$ da população que ainda vive no meio rural, apenas $6 \%$ depende diretamente da agricultura, reflexo da expansão das atividades não agrícolas no espaço rural (NEDER; CARDOSO, 1998).

É nesse contexto generalizado de risco de permanência das famílias nas atividades agrícolas que Santa Izabel se encontra, visto que em tempos outrora a mandioca tinha significância socioeconômica neste município, sendo uma referência no estado do Pará. No entanto, em tempos mais recentes esta 
região representa apenas 1.000 toneladas da produção de mandioca (IBGE, 2009).

Destarte, o estudo busca explicar os elementos pertinentes que contribuíram para o declínio acentuado da produção de mandioca, Gap este que certamente afetou as variáveis de emprego, renda e de PIB na economia do município de Santa Izabel. Neste aspecto, buscam-se respostas para alguns questionamentos, como: Quais fatores contribuíram para o declínio da produção de mandioca? O esgotamento do ciclo da produção de mandioca causou impactos significativos nas variáveis de emprego, renda e de PIB no município de Santa Izabel? Quem mais contribuiu com a economia local: foi à farinha de mandioca, quando as plantações de mandioca atingiram o ápice nos anos de 1970? Ou foi a farinha de tapioca, com o insumo importado?

Ao investigar e trabalhar estas circunstâncias, esta pesquisa se afasta dos demais estudos sobre a mandioca que, no geral, abordam apenas a comercialização da farinha de mandioca e/ou o mercado da mandioca, o que indica a importância e a singularidade deste trabalho, por aprofundar o conhecimento e a fundamentação teórica sobre esta cultura, algo tão pertinente para a ciência.

O objetivo do artigo é analisar os impactos socioeconômicos do declínio acentuado da produção de mandioca no município de Santa Izabel, destacando em que circunstância essa região deixou de ser referência no cultivo desta cultura, discutindo seus impactos para a economia local, notadamente na geração de emprego, renda e de PIB rural.

Acredita-se que os resultados deste estudo podem contribuir para revelar não apenas as principais as demandas, mas, contudo, aprofundar as discussões e análises das condições em que se reproduzem os produtores rurais, em particular na atividade da mandioca, cujos indicativos possam orientar as instituições públicas que promovem o desenvolvimento agrícola.

Além desta introdução, que descreve a proposta do trabalho, o conteúdo do artigo está alocado em duas partes distintas: procedimentos metodológicos, que mostram onde e como os dados da pesquisa foram coletados e trabalhados; e os resultados e discussão, que indicam os impactos do declínio da produção de mandioca para 
a economia local do município de Santa Izabel do Pará.

\section{MATERIAL E MÉTODOS}

O recorte espacial onde se desenvolve a pesquisa foi no Distrito de Americano (DA), situado próximo a BR-316 e a altura do km-36 no município de Santa Izabel do Pará que, por sua vez, se localiza na Amazônia oriental brasileira. A opção pelo DA se justifica por essa região ser representativa na produção de mandioca até os anos de 1980, cujo principal produto derivado - a farinha de mandioca garantia a ocupação, renda e PIB neste município.

Das dez unidades que compõe o DA (Galho Grande, Areia Branca, Santa Rosa, São Luiz, São Felipe, Uxiteua, Mocambo e Bairro do Sessenta) privilegiou-se a Colônia Ferreira Pena (CFP) e a Vila de Americano (VA), pois estes dois lugares são significativos nos domicílios alvos da pesquisa, isto é, as casas de farinha de tapioca, visto que são raras as casas que ainda produzem a farinha de mandioca.

Os sujeitos pesquisados foram, portanto, os produtores de farinha de tapioca, cuja unidade de analise foi o domicílio destes atores, no qual ficam os chamados 'retiros', locais onde se processa esse produto. O critério de seleção da população investigada foi àqueles que têm mais tempo de residência no DA, por terem mais experiência e conhecimento nas atividades da mandioca, bem como das mudanças as quais ocorreram no espaço rural do município de Santa Izabel.

Nas duas unidades pesquisadas (CFP/VA) foram visitados 32 domicílios, representando uma amostra de $30,5 \%$ do total das unidades produtivas de farinha de tapioca (105) em funcionamento no DA. Os dados da amostra foram coletados a partir do questionário, entendido como "uma técnica de investigação composta por um número mais ou menos elevado de questões e apresentadas por escritos às pessoas, tendo em vista o conhecimento de opiniões, crenças, sentimentos, experiências, expectativas de vida e de mundo" (GIL, 1995, p. 128). Pode ser concebido também como "um documento que visa gerar dados necessários para atingir os objetivos de um trabalho científico, a partir de um roteiro formalizado [...]” (MCDANIEL, 2003, p. 322). 
O conteúdo do questionário foi estruturado em duas partes distintas. A primeira busca descrever o perfil dos produtores de farinha do DA, sendo que esta parte foi alocada em oito blocos de perguntas do tipo aberta, fechada e de múltipla escolha. A segunda parte diz respeito à produção da farinha de tapioca, ou seja, trata-se dos registros econômicos deste processo produtivo, onde foi levado em consideração o insumo, mão de obra, produção, custo, receita e lucro da farinha de tapioca, indicando uma abordagem econômica do trabalho.

Os dados primários qualitativos da amostra foram explorados e operacionalizados através da técnica da distribuição de frequência, concebida como uma "técnica que compreende a organização dos dados de acordo com o número de ocorrências dos diferentes dados observados, cujos resultados em percentuais indicam o parâmetro da população investigada" (BARBETTA, 2005 , p. 39). Neste contexto, buscou se analisar a relação entre as principais variáveis quantitativas e qualitativas da população investigada como maneira de explicar a dinâmica da economia da mandioca e derivados no município de Santa Izabel. Por este motivo, a síntese das características da população investigada, bem como o seu contexto, se apresenta organizada em forma tabular e gráfica.

Os dados coletados foram tratados e analisados de maneira contábil, com a finalidade de constituir uma economia da produção de farinha de tapioca, com vista a mensurar a sua participação na produção de riquezas no município de Santa Izabel.

Além da pesquisa, recorreu-se aos dados secundários quantitativos do Censo Agropecuários do Instituto Brasileiro de Geografia e Estáticas (IBGE) e dos Anuários Estatísticos do Brasil, a partir dos anos de 1960, sobre a produção de mandioca no DA, quando o seu principal derivado era a farinha de mandioca. O resgate histórico destes dados tem a finalidade de descrever o ciclo da produção de mandioca, observando o seu ápice e seu acentuado declínio no município de Santa Izabel.

O sentido da pesquisa qualitativa e da pesquisa quantitativa foi comparar a economia da farinha de mandioca, quando o cultivo de mandioca ainda era representativo em Santa Izabel (1960/70), com a economia da farinha de tapioca (2009). Com este procedimento, busca-se a 
representatividade das respectivas atividades, apontando seus impactos na economia local, como também se busca a relação entre estas duas atividades no $\mathrm{DA}^{3}$.

Trata-se de uma abordagem histórica econômica sobre a cultura da mandioca e, por conta desta delimitação, o artigo não atingiu os $75 \%$ de periódicos científicos recentes dos últimos dez anos, como recomenda as diretrizes desta fonte publicadora, o que justifica a exploração de autores não tão recente para sustentar a pesquisa.

\section{RESULTADOS E DISCUSSÃO}

\section{A Tabela 1 disponibiliza dados} sobre a aquisição da fécula de mandioca e de mão de obra para a produção de farinha de tapioca, cujo período contábil, por semana, considerou a participação da CFP e da VA.

As unidades pesquisadas demandam 33 ton. de fécula de mandioca e 156 trabalhadores para produzir 103 ton. de farinha de tapioca,

${ }^{3}$ Em Santa Izabel do Pará, e em geral na Amazônia e região nordeste brasileira, o principal produto derivado explorado da raiz da mandioca é a farinha de mandioca. Todavia, com o esgotamento do ciclo da produção de mandioca, este município passou a produzir à farinha de tapioca, cujo insumo é a goma/fécula de mandioca. cuja maior participação e contribuição no processo produtivo é a VA. Esta disparidade de fatores e de produção entre as duas unidades pesquisadas também se reproduz nos registros econômicos da produção da farinha de tapioca, conforme indica a Tabela 2.

A receita total das unidades pesquisadas foi na ordem de $\mathrm{R} \$$ $76.965,00$ e o custo de produção foi de $\mathrm{R} \$ 45.323,40$; o que grou um lucro de $\mathrm{R} \$ 31.641,60$. Estes resultados econômicos são superiores na VA, ou seja, a CFP representa praticamente um terço dos resultados alcançados da VA.

$\mathrm{O}$ fato de a VA gerar maior contribuição para a economia de Santa Izabel pode ter explicação na sua própria localização, pois esta vila fica situada às margens da BR-316 e próximo do centro deste município, recebendo influências do processo de urbanização, resultando no desejo de prosperidade dos produtores da VA. Tanto é que os produtores da VA vêm obtendo algumas conquistas, como a parceria com o Governo Federal, que compra farinha de tapioca para servir de merenda nas escolas públicas, efeito da Cooperativa dos Produtores de Farinha de Tapioca de Americano (COOPFARTA). 
Tabela 1 - Insumo, mão de obra e produção semanal de farinha de tapioca no DA/2009.

\begin{tabular}{cccccc}
\hline Variáveis & VA & $\%$ & CFP & $\%$ & Total \\
\hline Insumo (ton.) & 22,575 & 67 & 11,1 & 33 & 33,675 \\
Mão de obra (Un.) & 110 & 70 & 46 & 30 & 156 \\
Produção (ton.) & 78,75 & 76 & 24,92 & 24 & 103,67 \\
\hline
\end{tabular}

Fonte: Pesquisa de campo no DA, 2009.

Tabela 2 - Registros econômicos semanal da produção da farinha de tapioca no DA/2009.

\begin{tabular}{cccccc}
\hline Variáveis & VA & \% & CFP & \% & Total \\
\hline Receita (R\$) & $59.940,00$ & 78 & $17.025,00$ & 22 & $76.965,00$ \\
Custo (R\$) & $32.516,00$ & 72 & $12.807,40$ & 28 & $45.323,40$ \\
Lucro (R\$) & $27.424,00$ & 87 & $4.217,60$ & 13 & $31.641,60$ \\
\hline
\end{tabular}

Fonte: Pesquisa de campo no DA, 2009.

Por outro lado, ao contrário da VA, a CFP se localiza no interior do DA, bem afastada da BR-316, cuja uma das características dos domicílios é o terreno grande, o que permite as famílias criar animais e plantar, ou seja, os produtores da CFP não dependem estritamente da produção da farinha de tapioca, o que justifica a pouca participação deste local no mercado, em função da renda extra ou ainda a tapioca funciona como complemento de renda na CFP.

Para Costa (2000) e de Abramovay (1992) o baixo registro econômico de uma atividade rural pode ser considerado como normal, na medida em que o objetivo primário dos estabelecimentos seja a reprodução social do grupo familiar, ficando em segundo plano os ganhos econômicos com a produção. Abramovay (1992) também apresenta outra explicação para a pequena produção familiar, como na CFP, de que a decisão de não produzir em grande quantidade faz parte da estratégia dos produtores rurais, isto é, comercializar farinha ou reservá-la para o consumo familiar não significa que o mercado deixe de ser levado em consideração, e sim, que o camponês atua segundo uma estratégia na qual o grau de integração com o mercado ocorre de maneira parcial.

Por esta fundamentação, então, não se pode mensurar o desempenho ou bem estar das famílias rurais pela quantidade que produz, pois a unidade pode ter como objetivo não o mercado, mas a subsistência dos membros da família. 
Por isso, que Hurtienne (2005) chama atenção de que não se pode tratar a pequena produção agrícola como um setor que representa atraso e/ou avesso a modernização no espaço rural, sob o risco de se fazer interpretação equivocada do estabelecimento rural.
Outro ponto a ser destacado na atividade da farinha de tapioca é a ocupação da mão de obra, cujos dados contabilizados se encontram organizados na Tabela 3, que compara a População Ocupada (POC) do ramo da farinha com a POC do município de Santa Izabel.

Tabela 3 - A POC das casas de farinha de tapioca no conjunto da POC do município de Santa Izabel/2008.

\begin{tabular}{lll}
\hline Principais categorias & Contagem & $\%$ \\
\hline População Economicamente Ativa (PEA) & 21.785 & 100 \\
POC em Santa Izabel (A) & 15.249 & 69 \\
POC nas casas de farinha (B) & 525 & 24 \\
(B)/(A) & - & 4 \\
\hline
\end{tabular}

Fonte: Censo demográfico do IBGE (2008); pesquisa de campo no DA, 2009.

Considerando que a média de demanda por mão de obra nas unidades produtivas de farinha de tapioca é de cinco trabalhadores e que tenha um total de 105 farinheiras, então este setor demanda próximo de 525 trabalhadores. Este contingente de trabalhadores representa $24 \%$ da PEA de Santa Izabel; e apenas $4 \%$ da POC deste município. Esta participação pode ser considerada baixa, indicando a natureza da farinha de tapioca em demandar pouca mão de obra, pois o insumo importado e pronto reduz o processo produtivo em transformar a goma em apenas pequenos grãos para serem torrados.
Não obstante este pequeno percentual dos trabalhadores da tapioca, a geração dos 525 postos de trabalho neste segmento é significativa, pois não se pode perder de vista que do total da PEA de Santa Izabel (21.785) $30 \%$ (6.536) se encontra desocupada neste município. Cabe lembrar que se o número de unidades produtivas desativadas (45) voltasse a funcionar no DA, o ramo da tapioca certamente poderia ampliar a oferta de emprego, contribuindo para reduzir o desemprego em Santa Izabel. Mais que indicar a pouca ocupação de trabalhadores na tapioca, é interessante frisar que a 
maioria dos ex-agricultores de mandioca não conseguiu se ocupar neste segmento, deslocando-se para outras atividades ou para os centros urbanizados.

A importância da mandioca para as famílias rurais do município de Santa Izabel não pode ser entendido apenas em tempos outrora, quando o DA era referência na produção desta cultura, pois em tempos mais recentes a mandioca ainda marca a sua posição de destaque no contexto das lavouras temporárias, como mostra os dados da Tabela 4.

Tabela 4 - Valor nominal (mil R\$) das lavouras temporárias (ton.) no município de Santa Izabel, em 1994/2004/2006.

\begin{tabular}{c|c|c|c}
\hline Lavouras temporárias & 1994 & 2004 & 2006 \\
\hline Feijão & 36 & - & - \\
Milho & 2 & - & - \\
Abacaxi & - & - & - \\
Melancia & - & - & 120 \\
Mandioca & 180 & 120 & 120 \\
\hline Total & 218 & 120 &
\end{tabular}

Fonte: Produção agrícola municipal/ IBGE, 2007.

Na Tabela 4 demostra-se que, exceto a mandioca, as culturas das lavouras temporárias desaparecem no cenário rural do município de Santa Izabel, ou seja, a partir do ano de 2004 a única cultura ainda presente na paisagem rural deste município é a mandioca, reproduzindo-se no último período, com um valor de $120 \mathrm{mil}$ Reais, embora tenha apresentado uma queda de $33 \%$, quando comparado com o primeiro período.

A mandioca, portanto, ainda representa a lavoura temporária no município de Santa Izabel, embora sejam raras as plantações no DA. Esta constatação reforça a importância da mandioca e derivados para as famílias rurais não apenas deste município, mas da Amazônia, até porque esta cultura é plantada nos 143 municípios paraenses (SANTANA; AMIN, 2002). Neste aspecto, o declínio da produção de mandioca no DA abriu uma lacuna de ocupação, de geração de renda e, principalmente, representou perda de identidade para este local ${ }^{4}$.

\footnotetext{
${ }^{4}$ Estudos apontam que a região bragantina, cujo um dos fluxos populacionais ocupou a região de americano, se desenvolveu a partir da produção de itens de primeira necessidade, como farinha
} 
Além da ocupação e a importância da mandioca, é interessante se mensurar o desempenho econômico da atividade da tapioca, comparando-se este segmento com a receita gerada na agropecuária, tendo como parâmetro o PIB de Santa Izabel, disposto na Tabela 5.

Os dados da Tabela 5 indicam que enquanto a receita da agropecuária participa com 18,91\% no PIB de Santa Izabel; a farinha de tapioca representa 17,62\%. O desempenho econômico da tapioca é próximo da agropecuária, indicando a sua forte participação e contribuição na geração de divisas para a economia local.

Estes resultados da economia da farinha de tapioca no conjunto da produção de riquezas contrariam a problemática do acentuado declínio da produção da mandioca em Santa Izabel, visto que o DA não produz o insumo para este produto. A estratégia dos exagricultores de mandioca foi importar a goma, que permitiu a produção da farinha de tapioca, mito embora essa atividade pouco internalize a renda gerada, pois $38 \%(\mathrm{R} \$ 29.396,00)$ da sua

de mandioca, para abastecer os seringais no interior da região amazônica, por volta de meados do século XIX. Por isso, o Distrito de Americano passou a ser associado à mandioca, notadamente à farinha de mandioca. receita $(\mathrm{R} \$ 76.965,00)$ são destinados ao estado do Paraná como pagamento do insumo.

A concorrência da produção paranaense pode ter sido um dos elementos que afetou a produção de mandioca local, pois a farinha de mandioca perpassa por vários processos, demandando tempo e muito esforço físico. Por outro lado, na tapioca o processo se limita a confecção dos grânulos, mais a sua torrefação.

Para maior aferição do desempenho econômico da tapioca, tomou-se como base os dados do Censo agropecuário do IBGE dos anos de 1970, que dispõe de indicadores da atividade da farinha de mandioca, quando a mandioca ainda era representativa em Santa Izabel, com a finalidade de se comparar os resultados destas duas atividades, segundo a Tabela 6. 
Tabela 5 - Participação (\%) da agropecuária e da tapioca no PIB do município de Santa Izabel/2008.

\begin{tabular}{ccc}
\hline PIB & Valor (R\$) & Participação (\%) \\
\hline Santa Izabel & $179.506,00$ & - \\
Agropecuária & $33.927,00$ & 18,91 \\
Tapioca* & $31.641,60$ & 17,62 \\
\hline
\end{tabular}

* Lucro contábil das casas de farinha de tapioca pesquisadas

Fonte: Contas regionais do IBGE, 2008.

Tabela 6 - Comparação dos resultados econômicos da farinha de mandioca (1970) com a farinha de tapioca (2009) no DA.

\begin{tabular}{|c|c|c|c|c|c|}
\hline Variáveis & $\begin{array}{c}\begin{array}{c}\text { Farinha de } \\
\text { mandioca }\end{array} \\
1970\end{array}$ & $\%$ & $\begin{array}{c}\begin{array}{c}\text { Farinha de } \\
\text { Tapioca }\end{array} \\
2009\end{array}$ & $\%$ & Total \\
\hline Mão de obra (Un.) & 1.866 & 92 & 156 & 8 & 2.022 \\
\hline Produção (t) & 3.774 & 43 & $4.944^{2}$ & 57 & 8.718 \\
\hline Valor da receita $(\mathrm{R} \$)$ & $9.131,05^{*}$ & 22 & $31.641,60$ & 78 & $40.772,40$ \\
\hline Participação no PIB $(\mathrm{R} \$)^{1}$ & 115.408 & 7,9 & 179.506 & 17,62 & - \\
\hline
\end{tabular}

1 Valor da receita sobre o PIB.

${ }^{2}$ Por semana as duas áreas pesquisadas produziram um total de 103,67 t de farinha de tapioca, sendo que por mês isto significou $412 \mathrm{t}$ e, por ano, este indicativo representou uma produção de $4.944 \mathrm{t}$ de tapioca.

*Valores nominais corrigidos e atualizados pelo Índice Nacional de Preço ao Consumidor, INPC do IBGE (BACEN, 2009).

Fonte: Censo agropecuário do IBGE, 1970/ Pesquisa de campo no DA, 2009.

Em termos de receita, a Tabela 6 mostra que a farinha de tapioca $(\mathrm{R} \$$ $31.641,60)$ é bem superior a farinha de mandioca $(\mathrm{R} \$ 9.131,05)$, representando $78 \%$ do total das receitas das duas atividades ( $\mathrm{R} \$ 40.772,40)$, contra $22 \%$ da farinha de mandioca. Também a tapioca garante maior participação no PIB de Santa Izabel (17\%); enquanto a farinha de mandioca participou apenas com $7 \%$. Ou seja, exceto a quantidade de mão de obra (1.866), no ano de 2009 os demais indicativos são superiores na atividade da farinha de tapioca, o que corrobora seu bom desempenho econômico.

Segundo a Tabela 6, a atividade da farinha de mandioca exige grande contingente de trabalhadores, confirmando ser fonte de fixação e de ocupação das famílias no campo. Outro ponto a ser destacado é a quantidade produzida da tapioca, em relação à farinha de mandioca, o que garante maior resultado econômico àquela atividade. Esta diferença de produção pode residir no tempo e no dispêndio físico que estes dois tipos de farinha levam para serem produzidas. 
A farinha de mandioca exige inúmeras tarefas para ser produzida, tal que, nos anos de 1970, enquanto o mesmo agente plantava, colhia, produzia a farinha de mandioca, a goma e a farinha de tapioca, ocupando de várias atividades ao mesmo tempo; em 2009 o agente produtor se especializou apenas em uma tarefa: a produção de tapioca, visto que adquire o insumo beneficiado do Esaraná, o que possibilita maior quantidade produzida.

Muito embora do destaque econômico da economia da tapioca frente a farinha de mandioca, as unidades pesquisadas vêm encontrando dificuldades para se reproduzirem no DA, pois a forte dependência do insumo é apenas o lado mais visível da questão. Esta situação se agrava quando se nota as oscilações constantes no preço da fécula de mandioca que é fruto do aumento da demanda por este insumo, o qual vem sendo bastante requisitado em distintos ramos industriais, com relevância ao setor de alimentação, papelão e têxtil (ASSOCIAÇÃO, 2005). O elevado preço da goma certamente se reflete também na oscilação das casas de farinha de tapioca, não é por acaso que 45 unidades estão desativadas.
Além da dificuldade da aquisição do insumo, a atividade da tapioca vem enfrentando imposições dos órgãos ambientais, que impedem a produção e comercialização de lenha, a qual alimenta os fornos para torrar a farinha. Também se constatou que os órgãos da infância e da adolescência vêm proibindo os membros das famílias a desenvolverem atividade de trabalho, aplicando multa, tendo o produtor que contratar mão de obra. "As famílias tradicionais vêm sofrendo choques de fatores externos [...] Não se transmite quase mais nada aos filhos: nem fortunas, nem profissão, nem crenças e nem saberes" (PERROT, 1993, p. 79), indicando risco de continuidade das atividades rurais dentre os membros familiares.

O escoamento da produção ${ }^{5}$ é outro ponto importante da atividade da farinha de tapioca, pois o valor pago ao produtor influencia na reprodução da atividade, bem como no bem estar familiar. A comercialização da produção das unidades pesquisadas pode ser visualizada na Tabela 7 .

\footnotetext{
5 Até os anos de 1970 a produção do DA e adjacências era escoada pelo trem o qual fazia a linha Belém /Bragança. Com a sua desativação, a distribuição e comercialização dos produtos da mandioca, em evidência à farinha de mandioca, ficaram comprometidas, o que repercutiu na retração do cultivo de mandioca.
} 
Tabela 7 - Formas de comercialização da produção de farinha de tapioca no DA.

\begin{tabular}{l|c|c|c|c}
\hline \multirow{2}{*}{ Comercialização da produção } & \multicolumn{2}{|c|}{ VA } & \multicolumn{2}{c}{ CFP } \\
\cline { 2 - 5 } & Freqüência & $\%$ & Freqüência & \\
\hline & & & & 20,0 \\
Na unidade produtiva & 11 & 50,0 & 2 & - \\
Em pontos estratégicos & 4 & 18,2 & - & - \\
Em supermercados & 1 & 4,5 & 8 & - \\
Nas feiras livres & 4 & 18,2 & 0 & 100,0 \\
Outros & 2 & 9,1 & 10 & 100,0 \\
\hline Total & 22 & 100,0 & & \\
\hline
\end{tabular}

Fonte: Pesquisa de campo no DA, 2009.

Os dados disponíveis na Tabela 7 que, enquanto na VA $50 \%$ dos produtores comercializam a sua produção na própria unidade produtiva , na CFP $80 \%$ dos produtores comercializam o seu produto nas feiras livres e apenas $20 \%$ realizam a venda na própria unidade produtiva. Quanto a venda ao setor varejista, apenas a VA consegue realizar comércio com os supermercados $(4,5 \%)$.

Segundo os produtores o preço na unidade produtiva custa $\mathrm{R} \$ 45,00$ a saca com 100 litros de farinha de tapioca, ou R\$ 0,45 o litro. Nas feiras livres, estas mesmas quantidades equivalem $\mathrm{R} \$$ 50,00 e $\mathrm{R} \$$ 0,50, respectivamente, representando um incremento de $10 \%$ ao preço praticado na porta dos estabelecimentos produtivos. Esta diferença de valor significa que os produtores da CFP conseguem melhores preços pelo seu produto.
Por outro lado, a venda na unidade produtiva tem como presença marcante a figura do agente intermediário, tão discutido por Figueiredo (2001), cujo papel é fazer chegar o produto até o mercado consumidor, porém com o preço onerado ${ }^{6}$. Segundo os interlocutores da VA a preferência da comercialização da produção na unidade produtiva ocorre em função de representar uma 'venda certa', embora o preço recebido seja inferior ao praticado nas feiras livres de Belém.

Santana e Amin (2002) definem os agentes intermediários, ou atravessadores, como os agentes que se encarregam de reunir grande quantidade do produto a partir do transporte próprio. Atuam a serviço dos atacadistas que distribuem o produto no mercado

\footnotetext{
${ }^{6}$ Embora o preço pago ao produtor seja de $\mathrm{R} \$$ 0,45 , nas feiras livres encontra-se o produto por $\mathrm{R} \$ 1,50$ a $\mathrm{R} \$ 2,00$, sendo uma diferença de mais de $100 \%$. No ramo da farinha de mandioca este esquema se reproduz de forma semelhante.
} 
local, assim como para outras unidades de federação. González e Helfand (2003) consideram que a participação do agente intermediário na cadeia de comercialização da farinha ${ }^{7}$, e outros produtos, inviabilizam que os produtores se integrem ao mercado, impedindo conhecer a demanda pelo seu produto, além de pouco conhecer a dinâmica do mercado o qual atuam.

A participação dos agentes intermediários na atividade da tapioca é outro elemento que pressiona as unidades produtivas, na medida em que desloca renda dos produtores, subtraindo recursos para serem reinvestidos seja na aquisição de insumos ou na reprodução do bem estar familiar. Não é difícil imaginar que no auge da produção da farinha de mandioca esta atuação era mais acentuada, onde riquezas eram deslocadas para os atravessadores, afetando o preço do produto $^{8}$ e, com

\footnotetext{
${ }^{7}$ Estudos dão conta que são em torno de 13 agentes que participam na comercialização da farinha de mandioca na Amazônia (ver FIGUEIREDO, 2001).

${ }^{8}$ Recentemente pesquisas de Bezerra (2014) demonstraram que no final de 2012 o preço da farinha de mandioca se elevou de maneira astronômica, com uma variação de $90 \%$, quando a inflação do período foi de $6 \%$ e, em 2013, o produto continuou a subir aonde a farinha chegou a ser comercializada até por $\mathrm{R} \$ 7,00 \mathrm{o}$ quilo.
}

isto, contribuiu para o encerramento do ciclo da produção de mandioca.

É interessante notar que a atividade da farinha de tapioca sempre esteve presente no DA, inclusive desde os anos de 1960 esta produção já era marcante, contribuindo com ocupação, renda e PIB. Supõe-se que naquele tempo, a produção de mandioca garantia a produção de farinha de mandioca, além de tapioca, a partir da goma produzida $\begin{array}{llll}\text { artesanalmente. } & \text { A } & \text { Tabela } & 8\end{array}$ disponibiliza uma série histórica de 49 anos (1960/2009) da produção de mandioca, além da área plantada, e da produção de farinha de tapioca. 
Tabela 8 - Trajetória da área plantada e da produção da mandioca, comparada a produção de tapioca no DA (1960 a 2009).

\begin{tabular}{lccccc}
\hline Anos & $\begin{array}{c}\text { Mandioca } \\
\text { (Ton.) }\end{array}$ & $\begin{array}{c}\text { Variação } \\
(\%)\end{array}$ & $\begin{array}{c}\text { Área } \\
(\text { ha })\end{array}$ & $\begin{array}{c}\text { Variação } \\
(\%)\end{array}$ & $\begin{array}{c}\text { Tapioca } \\
\text { (Ton.) }\end{array}$ \\
\hline 1960 & 10.831 & - & 1.192 & - & 3.774 \\
1965 & 11.982 & 10,60 & 1.229 & 3 & - \\
1970 & 12.616 & 5,30 & 1.244 & 1 & 3.841 \\
1975 & 16.723 & 32 & 1.248 & 1 & - \\
1980 & 14.044 & -16 & 1.207 & -3 & 3.971 \\
1985 & 10.254 & -27 & 1.066 & -12 & - \\
1990 & 8.526 & -17 & 908 & -15 & 4.100 \\
1995 & 4.982 & -41 & 480 & -47 & - \\
2000 & 800 & -84 & 100 & -79 & 4.265 \\
2009 & 1.000 & 25 & 120 & 20 & $4.944 *$ \\
\hline
\end{tabular}

Fonte: Censos Agropecuários do Pará da FIBGE/IBGE, 1960/2009.

*Resultado contábil da pesquisa realizada no DA, 2009.

Neste recorte de 49 anos a produção de mandioca assume uma posição crescente, a qual se iniciou 10.831 ton., atingindo o ponto máximo 16.723 ton., em 1975, representando um crescimento significativo de $32 \%$. A partir deste marco, a produção de mandioca começa a se retrair, tendo maior visibilidade em 1980, quando a produção representou uma variação negativa $(-16 \%)$, ou seja, cresceu menos que a metade em relação ao período passado.

O declínio da produção de mandioca se reproduziu nos demais períodos até atingir o seu ponto mínimo com 800 ton., em 2000, cujo período marca o encerramento de um ciclo que perdurou por mais de cem anos no DA. A própria área planta da mandioca, nos anos de 1980, já anunciava o decréscimo da cultura, pois teve uma retração de $3 \%$, cuja variação negativa se reproduziu nos demais períodos de cultivo. Por outro lado, a farinha de tapioca apresenta crescimento positivo em todo o período em estudo, atingindo seu ponto máximo em 2009, com uma produção de 4.944 ton. A trajetória da produção de mandioca, ao lado da farinha de tapioca, no município de Santa Izabel apresenta maior ilustração de sua dinâmica no Figura 1. 
Figura 1 - Evolução da produção de mandioca (ton.) e da farinha de tapioca (ton.) no município de Santa Izabel, estado do Pará (1960 a 2009).

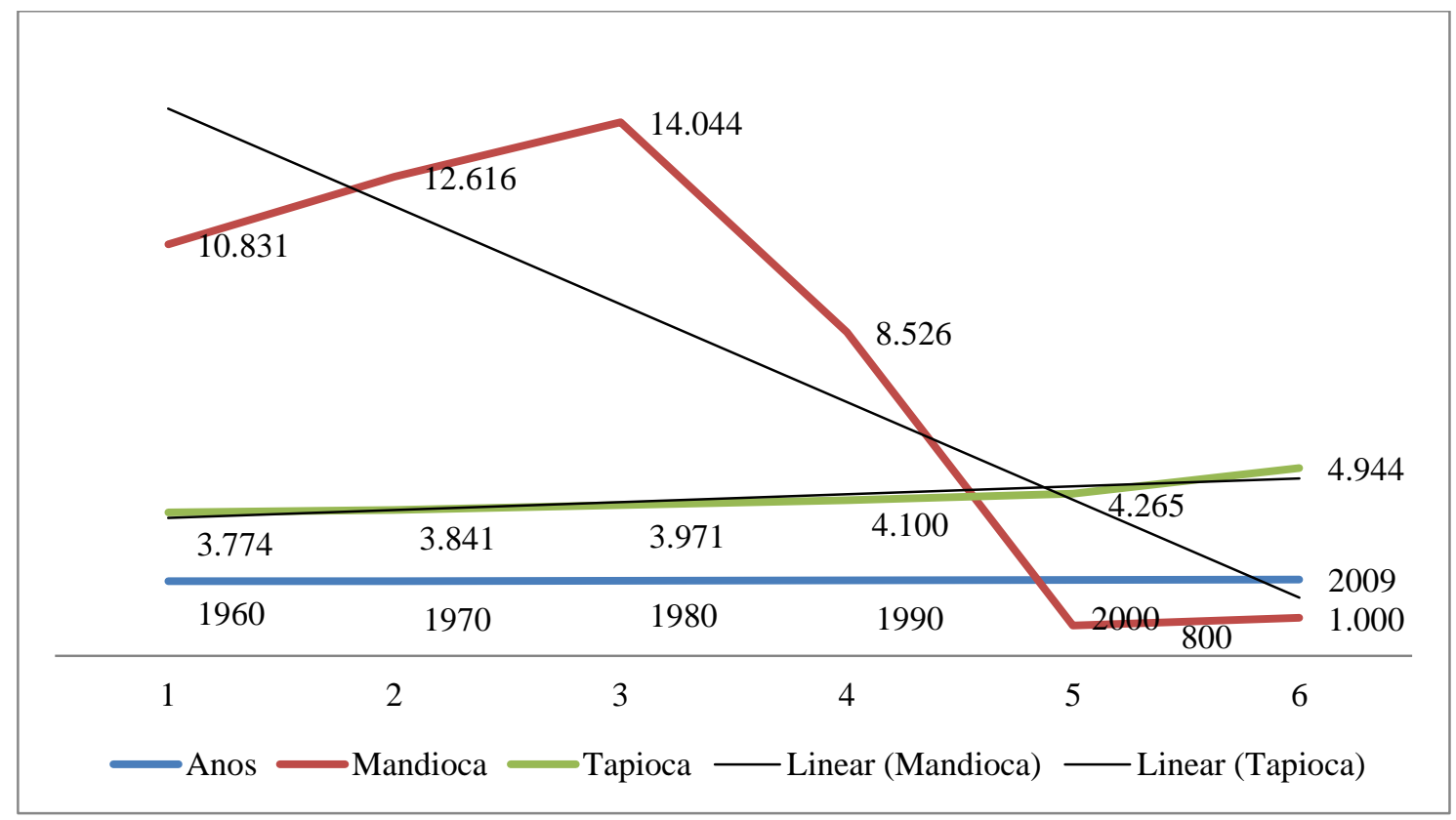

Fonte: Censo agropecuário municipal do IBGE (1960/2009).

Segundo a leitura da ilustração da Figura 1, após o ápice da produção mandioca por volta dos anos de 1975 (14.044 ton.), a produção da mandioca entra em declínio, cujo esgotamento é compensado pelo crescimento positivo da produção da farinha de tapioca, isto é, as duas curvas assumem trajetórias opostas a partir deste marco. Se por um lado, o ano de 1980 assinala o inicio do declínio do ciclo da produção da mandioca, como bem demonstra a linha de tendência. Por outro, a produção da farinha de tapioca se expandiu de modo significativo, aumentando a sua participação na economia do município de Santa Izabel.
Além do esgotamento de uma cultura e ascensão de outra, a Figura 1 indica a migração dos produtores de mandioca, e de farinha de mandioca, para o ramo da tapioca, onde a grande diferença é aquisição do insumo importado, ou ainda: a dependência do insumo importado determinou a continuidade da atividade da produção de farinha de tapioca, cujo impacto maior foi o encerramento do ciclo da produção de mandioca no DA, deixando de ser referencia desta cultura no município de Santa Izabel e no estado do Pará.

As mudanças que ocorreram nos campos do DA com a cultura da 
mandioca tem respaldo na fundamentação de Couto (1998), cujo pensamento é de que as atividades agropecuárias tradicionais vêm sentido o efeito do processo de urbanização do meio rural, como também pode ser resultado da expansão das atividades não agrícolas no campo (NEDER; CARDOSO, 1998). A produção da tapioca, inclusive, pode ser considerada com uma atividade não agrícola, e sim apresenta característica da 'indústria rural', visto que se trata de um processo de transformação da matéria prima ou do insumo, sendo realizada por técnica de trabalho simples e intensiva na habilidade manual, onde o conhecimento e a experiência assumem extrema relevância no desenvolvimento desta atividade.

A mandioca, diga-se de passagem, é uma cultura propicia para desenvolver a indústria rural em Santa Izabel, em função da possibilidade de oferecer inúmeros derivados e que podem ser extraídos de maneira artesanal, onde a produção da farinha de tapioca é apenas o lado mais visível desse processo. Enfim, o deslocamento dos produtores do cultivo da mandioca para a tapioca faz parte da dinâmica do setor agrário, cuja estratégia das famílias camponesas é se adaptar às mudanças no campo, como modo de se reproduzirem socialmente, inserindo-se, inclusive, em atividades não agrícolas, muito embora ainda permaneçam no espaço rural (COSTA, 2000).

O declínio do crescimento da produção da mandioca no DA pode ser fundamentado por vários elementos. Naquele período, enquanto as mudanças ocorriam no meio rural, na cidade de Santa Izabel novos elementos apareceram em cena, dinamizando a paisagem urbana, o que trouxe consequências para as atividades agrárias, em particular as culturas temporárias, como a mandioca. Foram vários fatores (internos e externos) à unidade produtiva que se manifestaram, criando um ambiente propício para que os produtores de mandioca não conseguissem mais se reproduzir, encerrando o ciclo da produção da mandioca no DA.

Os fatores internos à unidade produtiva foram àqueles que fizeram pressão dentro do próprio contexto do estabelecimento rural, afetando, de uma maneira ou de outra, o trabalhador e/ou a produção de mandioca, dentre os quais: o consórcio de culturas, pois a mandioca deve ser plantada ao lado de 
outras culturas, cujo resultado é a perder espaço no campo; depreciação do solo, fruto de mais de um século de exploração que, aliada a pratica de derrubada/queima, levou ao depauperamento das terras do DA; concentração fundiária, cujo processo ocorreu com a inauguração da penitenciária de americano, anos de 1970, onde muitas das terras foram comercializadas e convertidas em fazendas, onde a mandioca foi substituída pela pecuária.

Outros fatores também concorreram para acentuar o processo de declínio da produção da mandioca no DA, como a expansão das culturas permanentes, consequência das imposições ambientais, que levaram os produtores a substituir as lavouras temporárias, como a mandioca. A estes elementos adversos à mandioca, adiciona-se a falta de capacitação dos produtores, cujo lado mais visível desta situação é o baixo rendimento do cultivo e da produção de mandioca, efeito do processo produtivo manual e artesanal e do manejo da cultura, o qual se traduz na derrubada da floresta e queima para reaproveitar o solo já paupérrimo.

Quanto aos fatores externos à unidade produtiva se traduzem nos elementos que fizeram pressão no cultivo de mandioca de fora para dentro do estabelecimento rural, entre os quais se destaca: a chegada dos japoneses em Santa Izabel, os quais imprimiram na região a cultura da pimenta do reino, cuja maior valorização no mercado, nos anos de 1950, influenciou que muitos produtores se deslocassem para esta atividade, visto que o preço se elevara oito vezes mais que a mandioca (LUZ, 1994). A expansão da urbanização, efeito do crescimento da atividade avícola na cidade de Santa Izabel, foi outro elemento externo que concorreu com a mandioca, pois aumentou a demanda por trabalho, deslocando a população rural para a cidade, em busca por maior oportunidade de salários e de condições de vida.

Outros fatores exógenos à unidade produtiva da mandioca pressionaram esta atividade, como agroindústria da farinha, que resultou na divisão de trabalho, ou seja, enquanto os empresários produzem a farinha; muitos dos produtores se especializaram apenas na produção da mandioca, desequilibrando a produção de mandioca. O setor varejista que, ao entrar no circuito de distribuição dos produtos da mandioca, vem 
desestimulando os produtores, pois importa tais produtos do estado do Paraná. Para acentuar estas situações, predomina entre os produtores de mandioca a desorganização, pois os mesmos atuam de maneira desarticulada, permitindo a presença dos intermediários na cadeia de comercialização da farinha, o que representa deslocamento de renda do produtor para terceiros,

Portando, foram fatores diversos que contribuíram para o encerramento do ciclo da produção de mandioca no DA, com perda de referencia desta cultura no município de Santa Izabel, cujo efeito mais visível foi à migração dos ex produtores para a atividade da farinha de tapioca, porém adotaram como estratégia a importação da fécula de mandioca do Estado do Paraná.

\section{CONCLUSÕES}

$\mathrm{O}$ artigo buscou analisar os impactos socioeconômicos do declínio acentuado da produção de mandioca no município de Santa Izabel, a partir do Distrito de Americano, com pertinência as circunstâncias em que esta região deixou de ser referência no cultivo desta cultura e na produção de farinha de mandioca no estado do Pará, discutindo seus impactos para a economia local, notadamente na geração de emprego, renda e de PIB rural. Os dados copilados apontaram para os seguintes indicativos para os questionamentos levantados.

A pesquisa mostrou que os fatores que mais contribuíram para o declínio acentuado do ciclo da produção de mandioca no Distrito de Americano foram fatores de ordem interna (Consorcio de culturas, Concentração fundiária, Depreciação do solo, Falta de capacitação dos produtores, valorização das culturas permanentes, Desorganização dos produtores) e de ordem externa a unidade produtiva (Chegada dos japoneses, Expansão da urbanização, Agro industrialização da farinha, Crescimento do Setor varejista, presença dos intermediários) que, ao se combinarem de maneira (in)direta, criaram condições propicias para que os produtores não conseguissem mais se reproduzir quanto categoria nos campos de americano.

$\mathrm{O}$ estudo revelou que $\mathrm{o}$ esgotamento do ciclo da produção de mandioca pouco impactou na economia local, pois os ex-agricultores migraram para a atividade da farinha de tapioca 
garantindo as variáveis de emprego, renda e de PIB rural no Município de Santa Izabel, muito embora este segmento demande pouco volume de mão de obra, quando comparado com a atividade da mandioca.

Quanto à maior contribuição para a economia local, a pesquisa apontou que o maior dinamismo econômico ocorreu na farinha tapioca, pois esta atividade teve maior participação nas variáveis de emprego, renda e de PIB do município de Santa Izabel, quando em parâmetro com a produção máxima de mandioca nos anos de 1975. A maior contabilidade econômica em prol da tapioca se justifica pelo menor número de tarefas nesta atividade, determinado pelo insumo acabado, muito embora os produtores tenham que enviar próximo de $30 \%$ da receita gerada ao estado do Paraná para o pagamento da fécula de mandioca, indicando a pouco internalização da renda na economia local e a dependência do insumo.

Considera-se também que, assim como a trajetória dos produtores de mandioca teve a influencia de vários elementos, cujo fim último foi $\mathrm{o}$ esgotamento da produção; os produtores de farinha de tapioca também vêm sendo influenciados por fatores adversos a unidade produtiva, indo desde as restrições ambientais, que impede a aquisição de lenha, passando pelas imposições dos órgãos da infância e adolescência, que faz os produtores deslocar renda com aquisição de mão de obra contratada, até a desorganização dos produtores, a qual impede que estes agentes solucionem suas demandas. A dependência do insumo importado, a qual se reflete na oscilação das unidades produtivas em funcionamento, é apenas o lado mais notório deste contexto.

Portanto, o fenômeno que ocorreu nos campos de Santa Izabel reproduz o que vem acontecendo nos espaços rurais do Brasil e do mundo, asseverado por Couto (1998); Campos e Fernando (2003); Neder e Cardoso (1998), de que as atividades agropecuárias tradicionais vêm sentido os impactos do processo de urbanização do meio rural, com a expansão das atividades não agrícolas, representadas pela indústria rural. A farinha de tapioca não foge destas circunstâncias, pois esta atividade, embora esteja no campo, não faz parte da agricultura, como a atividade da mandioca, exigindo assim políticas diferenciadas.

Acredita-se que os resultados deste estudo tenham contribuindo para revelar 
as principais demandas dos produtores rurais, cujas circunstâncias que levaram ao encerramento do ciclo da produção de mandioca possam servir de indicativos para orientar as políticas públicas rurais, sob o risco de continuar reproduzindo $\mathrm{o}$ problema $\mathrm{da}$ permanência dos produtores no ramo da tapioca no DA e, de modo indutivo, nas atividades agrícolas afins no campo, colocando em cheque o desenvolvimento sustentável rural na Amazônia, muito embora esta proposição seja passiva de estudos investigativos mais aprofundados.

\section{REFERÊNCIAS}

ALBUQUERQUE, M. de. Mandioca. Belém: IPEAN, 1970.

A mandioca na Amazônia. Belém: SUDAM/IPEAN, 1996.

ABRAMOVAY, R. Paradigma do capitalismo agrário em questão. Campinas: ANPOCS, 1992.

ANUÁRIO ESTATÍSTICO DO BRASIL. Produção de mandioca por municípios do Brasil. Rio de Janeiro: IBGE, 1960.

Área destinada à colheita, quantidade produzida, rendimento médio e valor da produção, segundo as grandes regiões e unidades da federação produtoras de mandioca. Brasília, DF: IBGE, 2006.
Censo agropecuário do Brasil. Evolução da produção da mandioca. Rio de Janeiro: IBGE, 1970. (VIII Recenseamento Geral / Serie regional, v.3, Tomo IV).

Censo agropecuário: Pará. Produção da mandioca. Rio de Janeiro: IBGE, 1980. (IX Recenseamento Geral do Brasil, v. 2, Tomo 3, n. 6).

Censo demográfico: mão de obra no Pará. Rio de Janeiro: IBGE, 1980 (IX Recenseamento Geral do Brasil, v.1, Tomo 5, n.6).

- Censo Demográfico: dados gerais - Migração, instrução, fecundidade, mortalidade no Pará. Rio de Janeiro: IBGE, 1980 (IX recenseamento geral do Brasil, v.1, Tomo 4, n.6).

Evolução da produção agrícola por municípios e estados do Brasil. Rio de Janeiro: IBGE, 1975.

Evolução das lavouras temporárias e permanentes no Pará. Brasília: IBGE, 1995.

Evolução das lavouras no município de Santa Izabel do Pará. Brasília, DF: IBGE, 2004.

ASSOCIAÇÃO BRASILEIRA DOS PRODUTORES DE MANDIOCA (ABPM). Conjuntura atual do mercado de raiz e fécula de mandioca. Revista Abam. Paraná, v. 2, n. 10, p. 36-79, jun. 2005.

BANCO CENTRAL DO BRASIL. Correção de valores. Disponível em: <http://www4.bcb.gov.br/pec/correcao/ corrige.asp >. Acesso em: 26 Set. 2009. 
BARBETTA, P. A. Estatística aplicada às ciências sociais. 5. ed. Florianópolis: UFSC, 2005.

BEZERRA, F. de A. P. Crescimento da produção da mandioca e os impactos econômicos no nordeste paraense: o caso do Distrito de Americano no município de Santa Izabel do Pará. Belém, 2009, 199 f. Dissertação (Mestrado em Planejamento do Desenvolvimento) - Núcleo de Altos Estudos Amazônicos, NAEA/UFPA, Belém, 2009.

Preço Astronômico da farinha de Mandioca: Uma explicação Acadêmica. Disponivel em: <http://www.webartigos.com/artigos/pre co-atronomico-da-farinha-de-mandiocauma-explicacao-academica/103679/>. Acesso em: 24 Jan. 2014.

CAMPOS, F. R.; FERNANDO, J. F. A indústria rural no Brasil. Revista de Economia e Sociologia Rural. Brasília, DF, v. 41, n. 4, p. 44 - 89, Dez. 2003. (SOBER).

CARDOSO, C. E. Competitividade na cadeia agroindustrial da fécula de mandioca no Brasil: uma proposta de análise. São Paulo: ESALQ/USP, 1993.

COSTA, F. A. Economia camponesa e a dinâmica da invasão: o caso eloqüente de Capitão Poço. In: COSTA, F. Assis (Org.). Agricultura familiar em transformação no nordeste paraense: o caso de Capitão Poço. Belém: UFPA/NAEA, 2000.

COUTO, A. T. Artesanato: uma estratégia de sobrevivência da agricultura familiar. Revista de Economia e Sociologia Rural. Brasília, DF, v. 35, n. 1, p. 115-205, Jun. 1998 (SOBER).
CHAYANOV, A. Sobre a teoria dos sistemas econômicos não capitalistas. In: Silva, Graziano (org.). [S.1.], 1981.

EMPRESA BRASILEIRA DE PESQUISA AGROPECUÁRIA (EMBRAPA). Mandioca alimenta mais de 1 Bilhão de pessoas no mundo. Brasília, DF, EMBRAPA, 2005.

FIGUEIREDO, R. B. de. Elementos para uma economia política da mandioca: estratégias e proposições orientadas para o desenvolvimento local e regional. Novos Cadernos do NAEA. Belém, v. 4, n. 1, p. 120-215, Jun. 2001.

FOOD AND AGRICULTURA ORGANIZATION OF THE UNITED NATIONS. Produção global de mandioca. Roma, 2006. Disponível em: http://www.faostat.fao.org. Acesso em: 10 jan. 2008.

GIL, A. C. Pesquisa econômica. São Paulo: Atlas, 1995.

GONZÁLEZ, G. R.; HELFAND, S. Desenvolvimento econômico e os determinantes da integração espacial nos mercados agrícolas. In: HELFAND, Steven (Org.). São Paulo: Contexto, 2003.

GOODMAN, D. et al. Da lavoura às biotecnologias: agricultura e indústria no sistema internacional. São Paulo, Campus, 1989.

HOMMA, A. Em favor da farinha de mandioca. Gazeta Mercantil. São Paulo, 27 out. 2000. Disponível em: <http://www.investnews.net>. Acesso em: 27 fev. 2009. 
HURTIENNE, T. Agricultura familiar e desenvolvimento rural sustentável na Amazônia. Novos cadernos do NAEA. Belém, v. 6, n. 1, p. 19-71, Jun. 2005.

INSTITUTO BRASILEIRO DE GEOGRAFIA E ESTATÍSTICA. Normas de apresentação tabular. 3. ed. IBGE, 1993. Disponível em: <http://www.sei.ba.gov.br/norma tabul ar/normas_apresentacao tabular.pdf $>$. Acesso em: 20 Jun. 2009.

KAUTSKY, K. Questão agrária: proposta de preços mínimos para a agricultura. São Paulo: Contexto, 1987.

LOZANO, J. C. et al. Problemas no cultivo da mandioca. Cali: [s. n.], 1976.

LUZ, E. Farinheiros em busca da esperança perdida. Jornal A província do Pará. Belém, 5 maio 1994. Caderno economia, p. 3.

MCDANIEL, C. G. Pesquisa de marketing. São Paulo: Thompson, 2003.

NEDER, H. D.; CARDOSO, A. Evolução recente da estrutura de atividades e rendas no meio rural de
Minas Gerais. Revista de Economia e Sociologia Rural. Brasília, DF, v. 36, n. 4, p. 65 - 128, dez. 1998 (SOBER).

PERROT, B. A Composição familiar no campo. 2. ed. São Paulo: Contexto, 1993.

SANTANA, A. C. de; AMIN, M. M. Cadeias produtivas e oportunidades de negócios na Amazônia. Belém: UNAMA, 2002.

SILVA, J. G. da. O novo rural brasileiro. Campinas: Instituto de economia/Unicamp, 2002. (Coleção Pesquisas, n. 1).

SZMRECSANYI, T. Pequena história da agricultura no Brasil. São Paulo: Contexto, 1998. (Coleção repensando a história).

\section{AGRADECIMENTOS}

Ao $\mathrm{CNPq}$ pelo subsidio financeiro que permitiu condições materiais para realizar o curso de mestrado no Núcleo de Altos Estudos Amazônicos, NAEA, o qual derivou este artigo. 